\title{
Uncharted Territories: Developing digital experiences for anthropological and archaeological exploration
}

\author{
Kristin Carlson \\ Illinois State University \\ kacarl1@ilstu.edu \\ Amal Abdalla \\ Illinois State University \\ aaabdal@ilstu.edu
}

\author{
Lucy Gill \\ University of California, Berkeley \\ Lucy.gill@berkeley.edu \\ Annie Sungkajun \\ Illinois State University \\ asungka@ilstu.edu \\ Ella Jahraus \\ Illinois State University \\ ejjahra@ilstu.edu
}

\author{
Zahra Irranezhad \\ Illinois State University \\ ziranne@ilstu.edu \\ Sam Bruner \\ Illinois State University \\ sgbrun1@ilstu.edu
}

\begin{abstract}
This paper discusses the development of digital pedagogical and promotional tools for ongoing anthropological and archaeological work in the Darién Region of Panama. The Darién Region has been underexplored by archaeologists for the last century, and is home to the Darién Gap, the only break in the Pan-American Highway, which has, thus far, facilitated Indigenous sovereignty and protected endemic species. The authors have collaborated to share experiences of navigating the Darién Province of Panama through storytelling, adventure, and exploration with digital media. This project resides as a website with a variety of video and game works. Our goal is to have as much media available in both English and Spanish as possible, to be accessible to the local communities in Darién and to international communities, which is crucial to support locallyinitiated conservation initiatives. Current projects include videos documenting known populations that have migrated through the area, videos documenting a current anthropologist's explorations of the region, a game depicting a historical anthropologist's findings of an archaeological expedition from the 1920s, and accessible compilations of research on local flora and fauna.
\end{abstract}

Interactive experiences. Heritage. Public outreach.

\section{INTRODUCTION}

Although most of Darién Province is no longer as remote as most popular media would suggest, its lack of development has preserved one of the most culturally and biologically diverse ecosystems of the neotropical region. (Girot Pignot \& Pascal Oliver 2002). This project aims to create engaging media-based works that serve as educational and engagement tools both for the communities in the Darién region, as well as to global audiences about the history, ecology, and people of the Darién province of Panama. This paper focuses on the iterative nature of creating these media-based works: as new discoveries are made, new species are discovered, and new stories are told, we continue to iterate the video and game works to reflect this knowledge.
Despite the focus on remoteness and danger of most contemporary media articles, Darién Province is not uncharted in today's terms. It has had a vibrant history, which includes occupation by multiple Indigenous groups (Guna \& EmberaWounaan) since time immemorial; a Spanish settlement for 300 years; the oldest free Black settlement in the Americas, and many other longstanding Afro-descendant communities; and a short-lived colonization effort by Scotland (Velásquez-Runk 2017). Logging was so prevalent by the 1920's that it was noted that the biodiversity of the area was possibly the most studied in the Americas (Record \& Mell 1924, p.44). The dream of the Pan-American highway was explored in detail for many decades, to be halted out of ecological and agricultural concerns (VelasquezRunk 2017). Today, there is a rich diversity in the area due to the many people who have been there 
since time immemorial, and that travelled to the area and decided to stay.

The Digital Darién project is focused on developing digital tools for sharing experiences of navigating the Darién Gap in Panama through storytelling with digital media. The stories and datasets that are being used were collected by researcher Lucy Gill at University of California, Berkeley, who has been doing both in person fieldwork (until Covid-19), and remote crowd-sourced data collection (since Covid$19)$ in ecological history of the Darién region. The goal of this collaboration is to seek new ways of communicating the stories of working with community partners, as well as illustrating information about the area, and the anthropological work being done to reveal the history of the area.

This work developed through the author's discussions of how technology and digital media can better support and illustrate rural communities such as the Darién region. Works were developed through the collaboration of one author's direct, first-person fieldwork, and the other authors' second-person exploration of the stories and data provided to design and build the series of digital stories, experiences, and tools.

These projects have included deep collaborations in the research. The authors' second-person approach to the data included extensive time reviewing literature on the Darién Gap, exploring historical maps, ArcGIS data, the first-person notes, photographs, and interview data collected during fieldwork, and many conversations with Gill about her experiences of traveling through the area and developing relationships with community partners. The media works created were through an iterative process of design, assessing with the existing data, and reviewing with Gill and her experience of community partners. We emphasize the iteration, because media works are often considered to be "done" at a certain point. Our hope with this work is that we continue to iterate these works as new information becomes available. This paper illustrates these resulting projects, some of the history of the area that inform this work, and the process of decision-making in creating digital experiences of the Darién Province.

\section{BACKGROUND}

\subsection{Background data of the Darién region}

The Darién-Choco biogeographic region of Panama, the only terrestrial connection between North, Central and South America, has played a key role in animal, plant, and human mobility since its formation 2.8 million years ago (O'Dea et al. 2016). Today home to Afro-descendant,
Indigenous, and mestizo communities, as well as a transitory route for migrants from as far away as Africa and South Asia, Darién is still fundamental to cultural interchange. Contemporary narratives concerning Darién, however, have focused on its status as a political border as well as its wildness (Velásquez Runk 2015). Such narratives problematically portray this region as static rather than dynamic and ignore its deep anthropological and ecological histories. Darién Profundo, a collaborative archaeological and ecological project co-directed with Lucy Gill (University of California, Berkeley), Dr. Natalia Donner (Leiden University, The Netherlands), Dr. Tomás Mendizábal (Smithsonian Tropical Research Institute, Panama), and community partners throughout the province, was established specifically to challenge these implicit biases. The name of the project comes from a conversation with Noé Alvarado, a community leader, in which he described the depth of 'unadorned' Darién, including its significant but underappreciated local history. Perhaps because of these misconceptions, no formal archaeological research had been conducted in the region until our first season in 2019. PRíor to this, the only archaeological data from the province consisted of antiquarian exploration and unpublished reports (Cruxent 1957; De la Guardia et al. 1971; Drolet 1980; Fitzgerald et al. 2007; Linné 1929; McGiey 1964; Miranda \& De la Guardia 1971).

This lacuna is especially surprising given that Spanish colonists built their first settlements in mainland America within Darién and documented the complex Indigenous sociopolitical landscape that they encountered. For example, Vasco Núñez de Balboa described how the cacique (chief) of the Pearl Islands, off the Pacific coast from mainland Darién Province, exerted sociopolitical authority over the entire Gulf of San Miguel watershed (Bancroft 1883). This cacique's ability to maintain power was linked to his supeRíor seafaring capabilities and access to pearl-producing oysters - both dependent on Traditional Ecological Knowledge. This collaborative research project is working to create the first historical ecological chronology of the Gulf of San Miguel, focusing on the documentation of past and present landscape management practices that have affected ecosystem resilience.

Unfortunately, traditional ecological stewardship practices are under threat due to encroaching agrobusiness and logging interests. The wetland of Matusaragatí, for example, the largest source of freshwater in Panama and a refuge for endemic species, is being drained and de-vegetated. A team of ecologists from the Universidad Tecnologica de Panama who the Darién Profundo project collaborates with is documenting the contemporary biodiversity of this landscape and advocating for its 
conservation. However, at least one journalist and activist who has reported on the illegal activities of agrobusiness in the wetland has had her life threatened (Cardenas Castillero 2019). Therefore, it is crucial that the international community, and not just locals most at risk, be made aware of the fight for this important ecosystem. Additionally, maintenance of Indigenous sovereignty and the sovereignty of other traditional stewards is directly correlated with ecological resilience (Kimmerer 2011; Senos et al. 2006). Developing resources that engage international audiences but also promote Indigenous rights within the Panamanian legal system are crucial for the continued florescence of the region's ecology, recognized by UNESCO as a biodiversity world heritage site.

\subsection{Similar media works}

While there are many digital anthropology and archaeology projects, we focus on two projects to more deeply explore their design and interactions. Watterson et al.'s discussion of the SERF Hillforts Digital Project and the Nunalleq Educational Resource articulates how they worked collaboratively for co-design, illustrating multivocality of perspectives in the narrative, and created clear, interactive visuals to communicate with (2020). The web interfaces for both projects, while very different to suit the content and stakeholders, gives both an educational, engaging, and encompassing perspective to the content (Serious Animation 2021). For the SERF Hillforts Project, information is presented from an archeologist's point of view, at their desk. On the desk are samples, tools, and notes. The user can click on various items to discover more information about the dig, including a map of excavation sites with videos of the landscape and excavation, a selection of findings and information about them, and the researcher's notes about each excavation process and findings. This perspective gives the user a glimpse into both what the archaeologist does in the field, as well as back at their desk.

The Nunalleq Educational Resource is an application with a series of animated videos that enable the user to explore beautiful illustrations of life in Nunalleq. This is a very different approach than the Hillforts project, in that the user sees a day in the life of living in Nunalleq, rather than the perspective of the archaeologist. This articulately shows the collaboration between the local people of Nunalleq and the archaeologist, in that the videos include information both about stories and everyday activities of living there, as well as an archaeologist's discoveries based on samples collected in the area. While the format and art styles are quite different between the two projects, the style of the interface and the types of icons used are quite similar, showing them as part of the same project. The paper also notes that the creation of interactive interfaces can be at odds with the material culture of archaeology, "where material is measurable, functional and dateable but culture is less so, pertaining more towards livedexperience and contextual worldview" (Watterson et al. 2020, p.70). It is the balance of both the archaeological perspective, and anthropological perspectives that have informed our Digital Darién project.

In another project, Fortin navigates the reader through the journey of place-making, using interaction and digital means, in the exhibition $A$ Journey Into Time Immemorial with Coast Salish people (2017). This project was a collaboration between Simon Fraser University's Museum of Archeology and Ethnology and Stó:Iō-Coast Salish elders and knowledge keepers. However with the changing nature of technology, the platform the software was built on is now outdated, and the site was allowed to be downloaded and archived on the Siwal Si'wes Digital Library website (Siwal Si'wes Digital Library 2019).

The work A Journey Into Time Immemorial has seven exhibition spaces that explore the experience of telepresence and interaction to create a unique user experience. Fortin details the choices made, such as horizontal panning to slowly see a full panoramic perspective of the space, and the unique icons that appear as the user navigates the space with their cursor. Rolling over specific features, such as the door to the Longhouse, changes the cursor to a hand to simulate a sense of touching an item in order to enter, or touching an item to explore it more closely. Fortin also explores the pathways between perspectives and locations, noting that there are always many options of which direction to go. This is also revealed in the visual design choices; for example, the Beach and Longhouse-Front scenes exist in different times. So while the viewer experiences the work synchronously, both the navigational options and the visual design choices support different temporal histories of the area at once, giving the user a unique perspective to make sense of the place as not existing in only one point in time, but many. This work inspired the way our Darién project has conceived of the synchronous presentation of information and stories from different eras.

\section{PROJECT DESCRIPTIONS}

When the author's collaboration began, there were plans for Gill to travel to the Darién region in Summer 2020, to spend a significant period of time on fieldwork. Gill had developed community relationships, and was planning to deepen the 
research she had begun the summer prior. As collaborators, the authors were excited for her plans to continue her collection of community stories through photos, videos, and interviews. However, because travel was not possible at this time, we made alternative choices to work with the resources at hand.

One key component of the dataset that we had available, is that none of the artifacts that had been discovered were excavated. Everything was found by community partners, for example in their backyard garden, or while digging a well. The community relationships that Gill developed are central to the research, and to the projects we develop.

We wanted to ensure that we were illustrating the stories in a context, that we were not just creating videos and games from our distant, biased perspectives. As only Gill had travelled to the Darién Region, we rely on her stories and evidence for inspiration and guidance. All researchers additionally read the literature, looked at the history of Panama, and explored a variety of other similar projects. A Spanish-speaking voice actress was included in the projects, to record voice overs in the media, as well as translate and record in Spanish to more specifically reach community members in Darién and elsewhere in Panama. Iteration has been a key concept throughout this work, as a media work is frequently iterated as it is being created. This includes works that we believed to have been "finished". Many of our works so far were thought to be finished, but once we got a slightly different perspective, some additional data, or heard another viewpoint we have gone back to make more changes. As an academic project this seems to be important: that the media works can be flexible and living like the communities they are representing.

Media works can be found on the project website: https://kineticatat.github.io/DigitalDarien/

\subsection{Video: People of Darién}

The first video we created explores the historical diversity of people in the Darién region (see Figure 1). While to those who have only seen this region on the news, it may seem remote, undeveloped, and inhabited by only Indigenous people, the reality is quite different. There were multiple historic ventures to the Darién region: Vasco Núñez de Balboa first landed in Panama, in his attempts to find a new sea (and gold). A Spanish settlement was established and made Panama part of the Spanish Empire for many years.

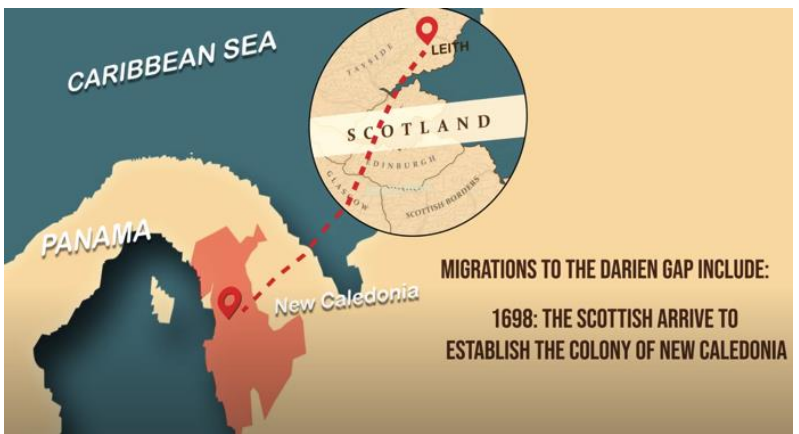

Figure 1: Still image of Scotland's colony establishment from the People of Darién Video.

Scotland's only attempt at colonization was also launched in the Darién but was a failure due to the Spanish's already strong presence in the area. The current population of the Darién region is very diverse, including people of Asian descent who travelled down from San Francisco to work on the Panama Canal; people of African descent who escaped slavery, or are currently migrating from African or the Carribean islands, as well as indigenous Wounan and Embera people (Velásquez Runk 2017). Very recently, there have been multiple stories about the treacherous journey that many migrants make to cross the Darién Gap in search of a better life in Mexico or the United States (Drost 2020).

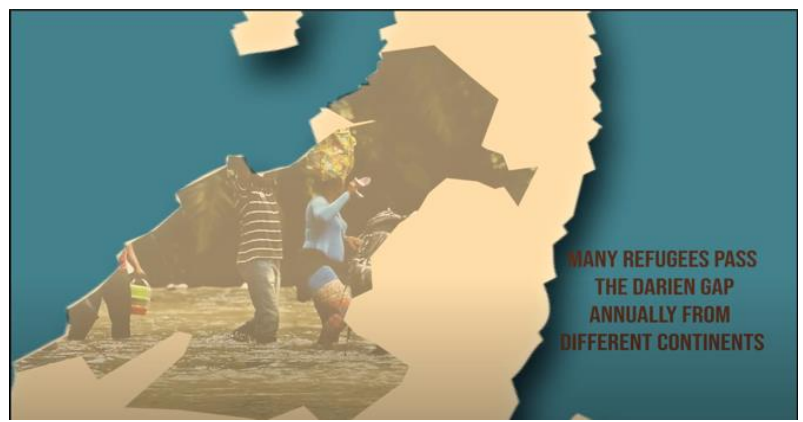

Figure 2: Still image from the People of Darién Video.

People of Darién explores the diversity of people in the Darién region (see Figure 1). This work highlights the location of Darién on the world map, the possible ways to get to the Darién province and cross the Darién Gap, and the variety of people that have travelled through the Darién region through history. This region has witnessed the migration of many different people to it and through it, such as Spanish conquistadors, Scottish explorers, Asian labourers, and freed slaves (see Figure 2). These settlements have engaged with and interacted with the local Wounaan, Embera, and Guna people, broadening and shifting our perspectives of what a "remote, uncharted" area is to the Western eye. 


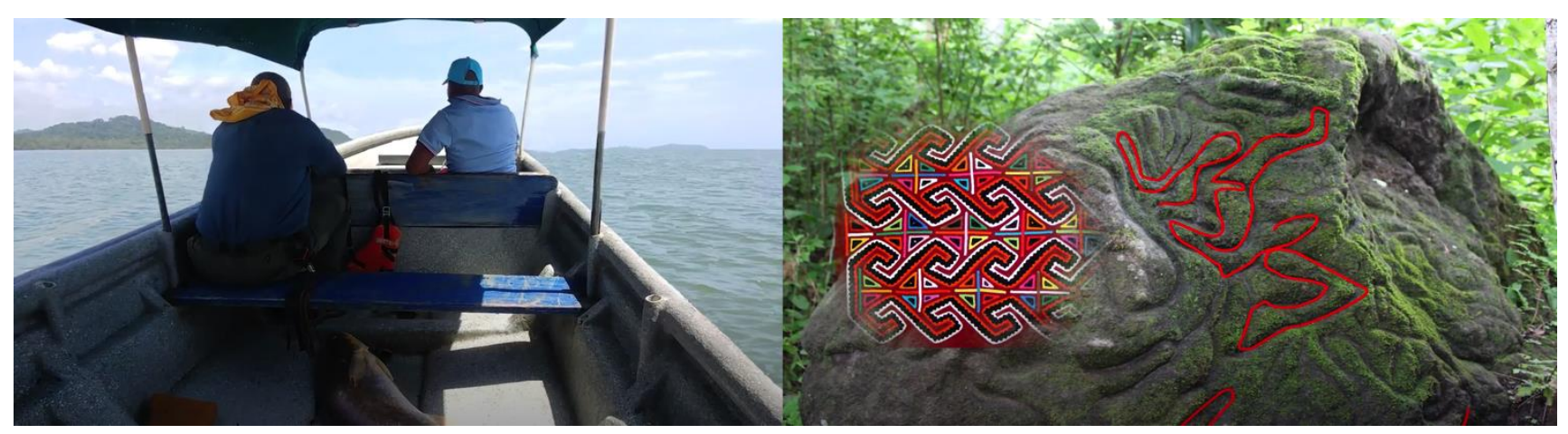

Figure 3: Shots from Travel to La Mola in Mogué.

This work was created by using motion graphics, illustrations of maps, and historical research of the area. A storyboard was created for each section of information, including camera movement, graphic designs, and related text. Google Maps was used to create accurate map templates in Photoshop, where colour and texture were edited to fit the design palette of the work. After Effects was used to create the motion graphics, utilizing tools such as mask, shape, trim path, title, and camera movement to convey non-text-based information. Music local to the region was used.

Our first few versions of the videos focused on the explorers who dominated the area for 300 years, as well as the recent news stories of migrants. As we found additional information about Santiago del Principe, the Afro-descendent community, the many people of Asian descent that relocated due to either work in the Panama Canal, or the logging interests, and the wave of hispanic people with the expansion of the Pan-American highway. These additions help us to craft the communication of prior stories, while not diminishing them.

\subsection{Video: Travel to La Mola in Mogué}

The second video developed out of a story told about meeting people in the village of Mogué, and being shown a large boulder carved with vaRíous designs. The researchers spent the night in the community's casa grande, a centrally-located, elevated structure with a thatched roof made from many different types of locally-harvested wood and plant products, and they ate a meal of boiled plantains and roasted rabbit, hunted and prepared by women in the community. Many samples were collected, and archaeological traces, including stone tools, were documented (see Figure 4). Travel to La Mola in Mogué highlights an archeologist's trip to the village of Mogué to see a unique rock that is known for its carvings (see Figure 4). Locals have known about the rock for centuries, but academic sources have not recorded it. The archeologist's team collected many samples of ceramics and unique plant species to study and further their understanding of the area and its history.

This video was constructed by using a variety of photos from the author's field research trip in 2019, and motion graphics. Motion graphics illustrated the similarity between Mola artwork and the designs on the boulder. This video was recorded in both English and Spanish, to best reach a variety of local and international audiences.

The narrative was written based on conversations with Gill, using images gathered from Darién. In order to provide a sense of motion, we used rotoscopy on all objects, and separated them from the background to be able to move each object individually. Adobe Premier was used to create motion with different objects. Blur and wave effects were added to add motion on water. To illustrate the Mola designs in the petroglyphs near Mogué, After Effects trim paths were used to show the similarities (see Figure 3). So far the content of this work has not needed to be iterated, but may be in the future.

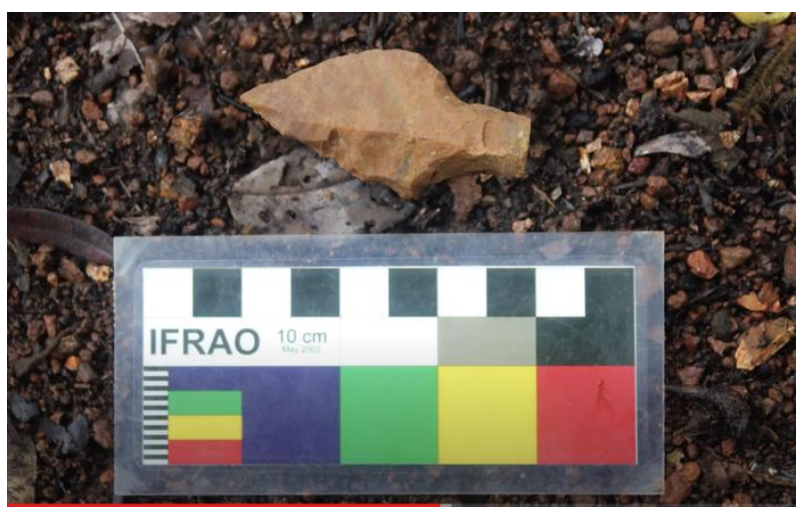

Figure 4: Still image of samples from Travel to La Mola in Mogué Video. 


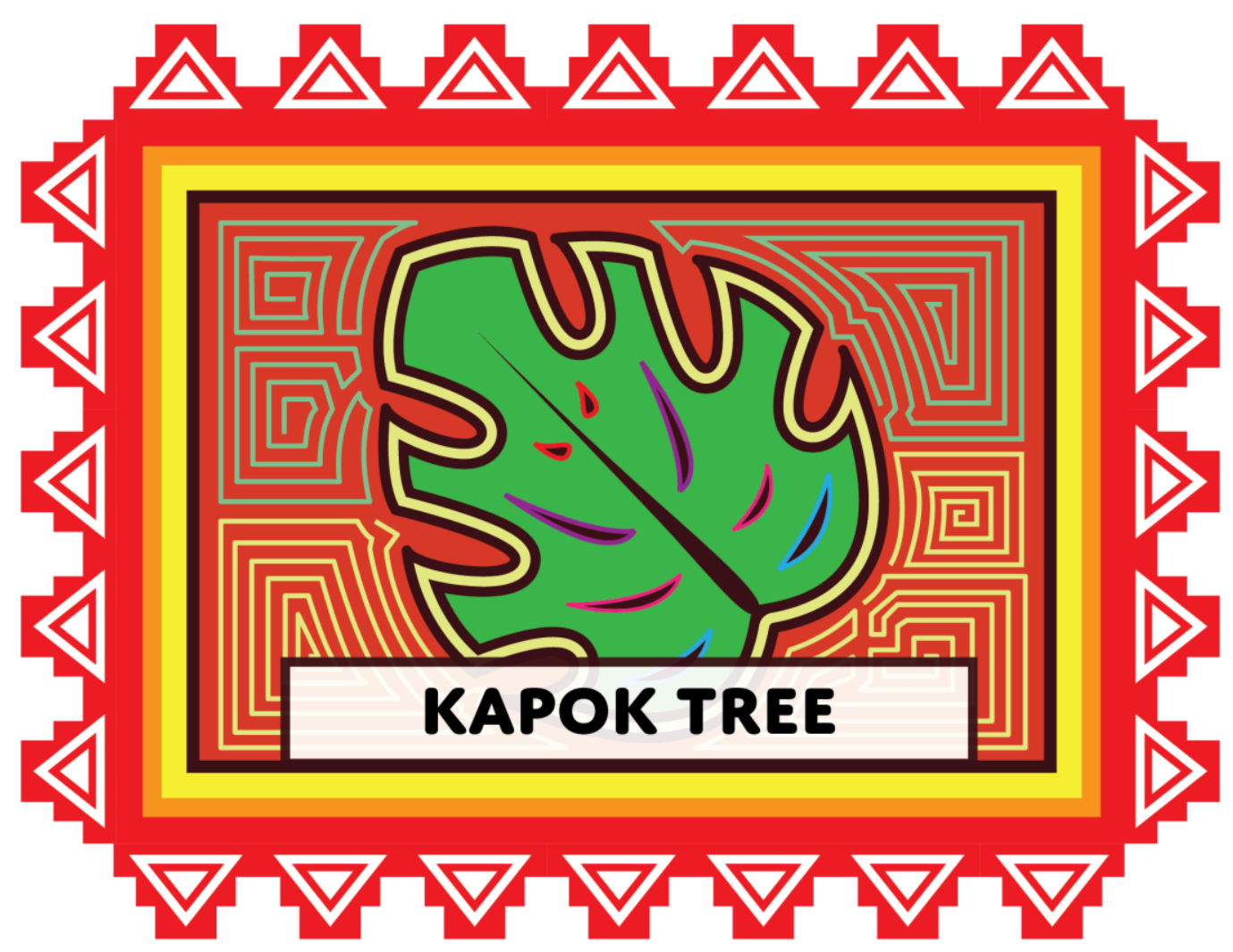

Figure 5: Sample card that can be found and added to the researcher's journal.

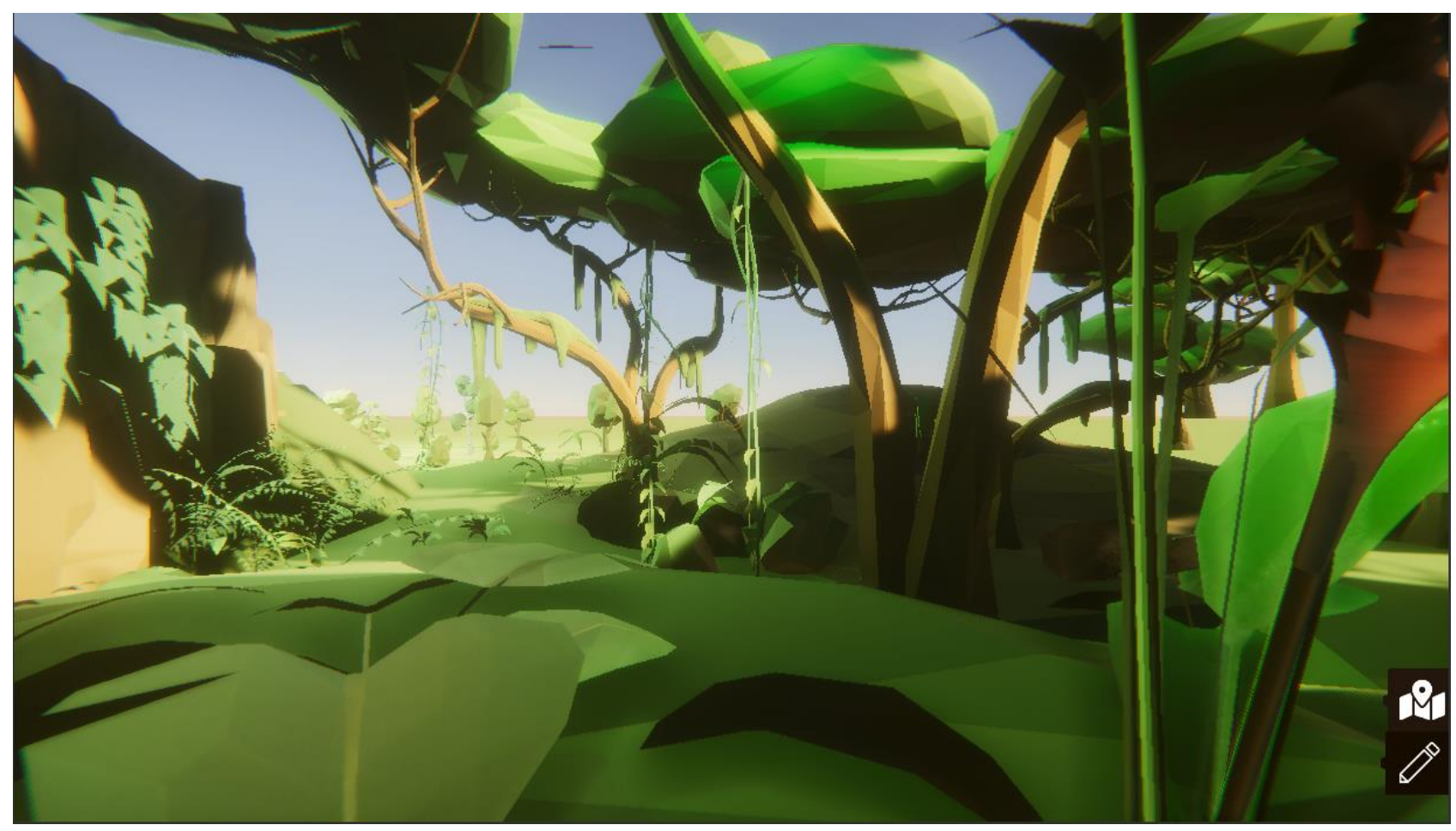

Figure 6: Game environment for Tracking Linné. 


\subsection{Game: Tracking Linné}

While video as a medium helps us illustrate specific facts and stories from the data, we also wanted to provide a more engaging platform that illustrates the experience of exploring this region. To work towards this, we designed a game to provide a deeper experience of exploring the Darién region. The game also acts as an educational resource for teaching about the topography, and local people, flora, and fauna.

The game Tracking Linné follows Gill, our field researcher's most recent trip, in which she follows the writings of Linné, a Swedish anthropologist, who took a 1929 trip to the Darién. By following the site descriptions and natural landmarks, the player can synchronously see the six areas that Linné explored in 1929, and the revisiting of Gill in 2019 and the new discoveries made. This approach to time is similar to that in $A$ Journey Into Time Immemorial as noted by Fortin in 2017 publication. The player explores the six locations, searching for the sites based on the geographic clues provided. Along the way the player collects "samples", representing different flora and fauna, filling up their journal of knowledge of the area (see Figure 5). What Gill does differently than Linné however, is collaborates with Indigenous and Afro-descendant community members in the Darién region and works with them to construct a different picture of the diversity and history of the area.

The game is designed in the Unity engine, using terrain.party's satellite-captured terrain maps to replicate the natural terrain of the unique locations that Linné visited, and where community partners live. The art styles of the game are inspired by photographs of the area, explorations of lighting in the rainforest, and archaeological findings. A combination of low-poly and more realistic assets are used to explore the abstraction of being caught between times (see Figure 6). While the current events and partners are very vivid and specific in our experiences, the historical understandings of the area are less concrete, and have less specificity.

The six sites that are explored in the game include: Río San Miguel, Río Santa Barbara, Punta Patino, Río Taimati, Río Chunga, and San Antonio. Our design choices for these sites are constructed from satellite data of the terrain, Gill's ArcGIS data of findings and samples collected, Linné's handdrawn maps of the area and object illustrations, and descriptions of the areas by community partners.

The player begins by meeting community members and hearing their stories. They progress to sharing historical items found in their backyards, gardens, and fields. The player takes photos and notes that go in their journal (see Figure 7). The player then travels to seek out the seven sites that Linné had previously explored (one was not able to be refound!) This is done by getting help from the local communities to find the general area of each site, following Linné's hand-drawn maps and drawings of geological landmarks, and using their archaeological knowledge to search for relevant items. The items are also photographed and added to the journal. In place of a traditional point-based reward system, the player accumulates items and adds them to their journal. This includes collecting photographs of flora and fauna along their journey. The more connections made with the community, and the more items that are found and documented, the more social capital is rewarded in trust with community partners.

To "complete" the game there are two different achievement screens. The first one, a "soft" ending, appears when the player has found all six of Linné's sites and travelled to them. This screen states that the player completed the primary goal, but they can continue collecting items and samples, as a researcher may do. The second screen appears once the player finds all the artefacts and finishes their journal. This screen will inform the player that they have found all the possible items at that time (though, in the spirit of iteration, this may change over time with updates to the research, and updates to the game).

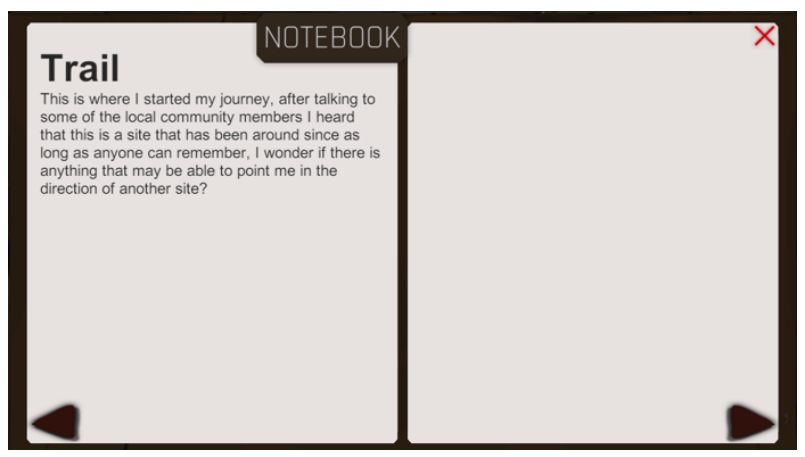

Figure 7: First entry in the player's research journal.

The game design has iterated quite a bit over development. It was started with high-dynamicrange rendering graphics in order to give an ultrarealistic visual of the area that we eventually decided was not reasonable, as the file sizes become very large, and would not be easy to load on more rural networks. We then shifted to other art styles of graphics (a mix of realistic and low-poly) to be more accessible, and were using a large single terrain map that included all of Linné's sites the in the Darién region, which are quite spread out across the region. This appeared to be too large of a space to explore, so we separated the sites into different scenes. This enabled smaller chunks of 
information for the player to explore, so again was more of an accessibility choice. We then began to question the focus on Linné specifically, and wanted to explore how to include community partners both in the content of the game, as well as in the achievements and mechanics of progressing through the game. Future iterations may include new species or artefacts that have been found in the area, new stories gathered from community partners, or emphasizing local conservation efforts in the gameplay and mechanics. Conservation in particular is a goal for future development, as it is a key issue to the Darién region.

\section{CONCLUSIONS}

This paper presents the design process of creating educational and outreach materials on the Darién Gap, in collaboration with anthropologist and archaeologist Lucy Gill. We acknowledge the importance of iterative media projects, as research is ongoing and new findings can significantly change a narrative or perception of information. Hence, this project focuses on the current state of three media works: two videos and one game. These works highlight a history of migration, a trip to visit community partners to see La Mola in Mogué, and the recent exploration of six sites originally visited by Linné. We continue to work with community partners to ensure that the perceptions being communicated through these works are correct and supportive, and have made choices such as recording narratives in both English and Spanish, and to have small file sizes or easy streaming to be accessible to as many communities as possible.

Design choices for these works have been made from a global perspective to the Darién region, specifically to work against the perceptions of it being a place of danger, pristine isolation, or mystery. We aim to highlight the collaborations with community partners, and the diversity of communities in the area.

\subsection{Future work}

While this paper describes three works (two video, one game) based on the Darién region, this work is ongoing, as it is iterative. There is currently a variety of additional videos, games, and educational resources being developed simultaneously to this publication. Especially exciting, is the development of a unique digital tool for supporting community-sourced data collection that is focused on user experience and promotion of community-based participatory research. Future work includes developing more educational resources on conservation for local Panamanian schoolchildren, supporting a local radio station (which is also the core source of historical, local stories) to broadcast as a podcast, as well as creating additional videos and games to illustrate the stories of the Darién region.

\subsection{Acknowledgements}

We would like to acknowledge and thank Teresa Estrada's voice acting work, Jennifer Price's website design, Mason Bates, Ola Oyedokun, Ethan Cossio, and Rochele Pereira-Gloor for their game design work, and their overall contribution to media content for this project.

\section{REFERENCES}

A Journey Into Time Immemorial. (2019, May 17). Siwal Si'wes Digital Library. https://swswlibrary.com/culture-and-history/ajourney-into-time-immemorial/

Bancroft, Hubert Howe. (1883). History of the Pacific States of North America. Vol. 6. San Francisco: A. L. Bancroft and Company, Publishers.

Cárdenas Castillero, Gustavo. (2019). “¿Quién: Es Ligia Arreaga?” La Prensa, January 3, 2019, sec. Opinion. https://www.prensa.com/opinion/LigiaArreaga_0_5205979455.html.

Cerwonka, A., \& Malkki, L. H. (2007). Improvising Theory: Process and Temporality in Ethnographic Fieldwork (New edition). University of Chicago Press.

Cruxent, José María. (1959). "Informe Sobre Un Reconocimiento Arqueológico En El Darién (Panamá)."

Drolet, Robert Patrick. (1980). "Cultural Settlement along the Moist Caribbean Slopes of Eastern Panama." PhD Dissertation, Urbana-Champaign: University of Illinois at Urbana-Champaign.

Drost, N. (2020, August 12). What migrants face as they journey through the deadly Darién Gap. In PBS NewsHour.

https://www.pbs.org/newshour/show/what-

migrants-face-as-they-journey-through-the-deadlyDarién-gap

Fitzgerald, Carlos, Mark Horton, and D. Theodossopoulos. (2007). "Report of Reconnaissance of Río Chico and Río Tuirre, Darién." Panama City.

Fortin, Claude. (2017). "Place-making With Telepresence: A Navigation Guide to A Journey into Time Immemorial's Seven Exhibition Spaces". The International Symposium of Electronic Art.

Isaac, G. (2008). Technology Becomes the Object: The Use of Electronic Media at the National Museum of the American Indian. Journal of 
Material Culture, 13(3), 287-310. doi: $10.1177 / 1359183508095497$

Kimmerer, Robin. (2011). "Restoration and Reciprocity: The Contributions of Traditional Ecological Knowledge." In Human Dimensions of Ecological Restoration, edited by Dave Egan, Evan E. Hjerpe, and Jesse Abra, 257-76. Washington, DC: Island Press/Center for Resource Economics. doi: $\underline{10.5822 / 978-1-61091-039-218}$

Levi-Strauss, C., \& Wilcken, P. (2012). Tristes Tropiques (J. Weightman \& D. Weightman, Trans.; Revised ed. edition). Penguin Classics.

Linné, S. (1929). Darién in the Past: The Archaeology of Eastern Panama and NorthWestern Colombia. Goteborg: Elanders Boktryckeri Aktiebolag.

McGiey, Charles. (1964). "Investigaciones Arqueologicas En Panama: Informes Preliminares Sobre Temporada 1961-1962." Hombre y Cultura 1 (3): 39-55.

Miranda G., Luis Maximo, and Roberto de la Guardia. (1971). "Prehistoria Del Distrito de Chepigana, Provincia Del Darién." Revista Tierra y Dos Mares 54.

O'Dea, Aaron, Harilaos A. Lessios, Anthony G. Coates, Ron I. Eytan, Sergio A. Restrepo-Moreno, Alberto L. Cione, Laurel S. Collins, et al. (2016). "Formation of the Isthmus of Panama." Science Advances 2 (8): e1600883. doi: 10.1126/sciadv. 1600883

Pandian, A. (2019). A Possible Anthropology: Methods for Uneasy Times (Illustrated edition). Duke University Press Books.
Physical Keys to Digital Memories: Reflecting on the Role of Tangible Artefacts in "Reminisce" । museuandtheweb.com. (n.d.). Retrieved December 22, 2020, from https://www.museuandtheweb.com/mw2011/paper s/physical keys to digital memories reflecting 0 . html

Record, S. J., \& Mell, C. D. (1924). Timbers of tropical America (Vol. 4). Yale University Press.

Senos, Rene, Frank K Lake, Nancy Turner, and Dennis Martinez. (2006). "Traditional Ecological Knowledge and Restoration Practice." In Restoring the Pacific Northwest: The Art and Science of Ecological Restoration in Canada, edited by Dean Apostol and Marcia Sinclair, 35. Washington: Island Press.

Serious Animation. (n.d.). Retrieved March 17, 2021. http://www.seriousanimation.com/

Velásquez Runk, Julie. (2015). "Creating Wild Darién: Centuries of Darién's Imaginative Geography and Its Lasting Effects." Journal of Latin American Geography 14 (3): 127-56. doi: 10.1353/lag.2015.0032

Velásquez Runk, J. (2017). Crafting Wounaan Landscapes: Identity, Art, and Environmental Governance in Panama's Darién. University of Arizona Press. https://muse.jhu.edu/book/49876

Watterson, A., Anderson, J., \& Baxter, K. (2020, July 1). Designing Digital Engagements: Approaches to creative practice and adaptable programming for archaeological visualisation. In: Weinel, J., Bowen, J.P., Diprose, G., and Lambert, N. (eds), EVA London 2020 (Electronic Visualisation and the Arts) 2020. doi: 10.14236/ewic/EVA2020.10 